Heterogeneous preferences for recreation-oriented

pÿmanagement in commercial forests : The role of citizens socioeconomic characteristics and recreational profiles

Juutinen, Artti

2017

Juutinen , A , Kosenius , A-K E , Ovaskainen , V , Tolvanen , A \& Tyrväinen , L 2017 , '

Heterogeneous preferences for recreation-oriented management in commercial forests: The

pÿrole of citizens socioeconomic characteristics and recreational profiles ' , Journal of

Environmental Planning and Management, vol. 60 , no. 3 , pp. 399-418 . https://doi.org/10.1080/09640568.2016.11

http://hdl.handle.net/10138/309071

https://doi.org/10.1080/09640568.2016.1159546

unspecified

acceptedVersion

Downloaded from Helda, University of Helsinki institutional repository.

This is an electronic reprint of the original article.

This reprint may differ from the original in pagination and typographic detail.

Please cite the original version. 


\title{
Heterogeneous preferences for recreation-oriented management in commercial forests: The role of citizens' socioeconomic characteristics and recreational profiles
}

Artti Juutinen $^{\mathrm{a}, \mathrm{b}, *}$, Anna-Kaisa Kosenius ${ }^{\mathrm{c}, 1}$, Ville Ovaskainen ${ }^{\mathrm{c}}$, Anne Tolvanen $^{\mathrm{a}, \mathrm{d}}$, Liisa Tyrväinen ${ }^{\mathrm{c}}$

${ }^{a}$ Natural Resources Institute Finland, P.O. Box 413, 90014 University of Oulu, Finland

${ }^{\mathrm{b}}$ Department of Economics, P.O. Box 4600, 90014 University of Oulu, Finland

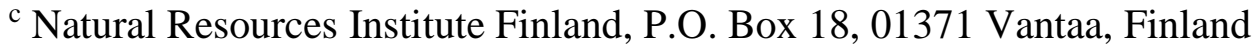

${ }^{\mathrm{d}}$ Department of Ecology, 90014 University of Oulu, Finland

${ }^{1}$ Present address: Department of Economics and Management, P.O. Box 33, 00014 University of Helsinki, Finland

* Corresponding author: Artti Juutinen, Natural Resources Institute Finland, P.O. Box 413, 90014 University of Oulu, Finland. Email: artti.juutinen@luke.fi, Phone: +358295325341

\begin{abstract}
The management of forests for multiple benefits, such as recreational services alongside timber production, can greatly benefit from the knowledge of public preferences for management-related forest attributes. This paper investigates citizens' recreational use and preferences for recreation-oriented management in the case of state-owned commercial forests in Finland using data from a choice experiment study. We focus on attributes related to the typical management practices applied to enhance recreation: scenic buffer zones along waters, game bird habitats, and the quality of scenery along hiking trails. Recreational use and its frequency were found to be related to citizens' background and specific outdoor activities. The scenic buffer zones were the most important attribute to the citizens. While the recreation-enhancing practices were generally valued, respondent segments with distinct preferences were found. Preference heterogeneity was related to citizens' socioeconomic characteristics and recreational profiles.
\end{abstract}

Keywords: forest recreation; multiple-use forestry; sample-selection model; choice experiment method; preference heterogeneity 


\section{Introduction}

As forests provide a multiplicity of amenity benefits, such as nature experiences, peace and quietness, physical exercise, beautiful landscapes, berries and mushrooms as well as attractive environments for hunting and fishing, they are widely used for outdoor recreation across Europe (e.g., FAO, 1988; Hummel, 1992; Roovers et al., 2002; Sievänen and Neuvonen, 2011; Ezebilo et al., 2015). In particular, recreational opportunities are provided by designated public recreational and conservation areas. The recreational use and benefits of such areas with little or no harvesting activities are covered by a large body of literature (e.g., Jensen, 1995; Tyrväinen et al., 2008; Manning, 2010). However, due to an increased public demand for enjoyable environments recreation has been integrated with timber production as a part of modern commercial forestry in many countries (Ribe at al., 1989; Nielsen et al., 2007; Gundersen and Frivold, 2008). In the Nordic countries Finland, Norway and Sweden, public as well as private commercial forests are used for recreation purposes based on the traditional right of common access ("everyman's right"). Especially in the management of state-owned forest lands the provision of public benefits such as recreation opportunities and biodiversity needs to be taken into account (e.g., Act on Metsähallitus, 2004).

The recreational benefits of multiple-use forests are affected by forest management practices through changes in the quality of the outdoor recreation experience. Landscape preference studies have shown that in particular regeneration practices with clear-cutting and intensive site preparation have a large impact on landscape values (Ribe, 1989; Silvennoinen et al., 2002; Gundersen and Frivold, 2008; Tyrväinen et al., 2008). Thus, information about citizens' preferences regarding the various forest benefits and forest management practices can greatly benefit the planning and management of multiple-use forests. Economic valuation studies have identified a number of management-related attributes that affect the recreational benefits of forests. These include, for example, tree species, evidence on forestry activities such as clearcutting, the size and shape of harvesting gaps, amount of trees left after harvest, and forest scenery related to management intensity (Hanley et al., 1998; Schaberg et al., 1999; Boxall and Macnab, 2000; Haefele and Loomis, 2001; Holmes and Boyle, 2003; Horne et al., 2005; Campbell et al., 2013; Tyrväinen et al., 2014). 
For a full understanding of citizens' preferences and their management implications, two issues require further research. First, the importance of a particular management attribute depends on the individual visitor's specific outdoor activity (Jackson, 1986; 1987; Christie et al., 2007; Tyrväinen et al., 2015). Therefore, information on factors affecting citizens' recreational use of forests and their recreational profiles in terms of visitation frequency and specific activities is needed. These factors may differ among regions, for example between rural and urban areas (Ezebilo et al., 2015). Second, as the preferences for specific forest management practices are likely to vary across individuals, alternative management practices are likely to involve both gainers and losers. Thus, it is crucial for informed management decisions to account for the heterogeneity of public preferences by identifying segments of citizens with distinct preferences.

This paper considers citizens' recreational use and preferences for recreation-oriented forest management in the case of state-owned commercial forests (SOCFs) in Finland. The SOCFs represent public lands managed for multiple benefits, notably timber and recreational services, on a statutory basis. We focus on attributes representing the management practices that are most typically applied to enhance recreation: scenic buffer zones along lakes and rivers, habitats for game birds, and the quality of scenery as reflected by the frequency of clear-cuts along hiking trails.

The paper contributes to existing literature as follows. First, we analyse individual-specific and activityrelated factors affecting the recreational use and visitation frequency in the areas using a sample-selection model (combination of binary and ordered probit models). Second, to elicit citizens' preferences for recreation-oriented management and their willingness to pay (WTP) for improvements in the recreational quality of the SOCFs, the choice experiment method is used. To investigate the heterogeneity in choice behaviour and WTP, we use the latent class model (Boxall and Adamowicz, 2002; Greene and Hensher, 2003). Juutinen et al. (2014) used the same survey data with random parameter logit (RPL) models to analyse Finnish people's valuation of the recreation-oriented management of SOCFs and to evaluate whether the recreational benefits produced justify the related loss of profits from timber sales. Although RPL models account for heterogeneity by allowing model parameters to vary randomly over individuals, they are not well-suited to explaining the sources of heterogeneity (Boxall and Adamowicz, 2002). This paper extends 
the previous study by elaborating on the heterogeneity of citizen's preferences with the latent class model (LCM). As the LCM allows the identification of distinct segments of preferences with their relative sizes and background characteristics, the approach is particularly relevant from a policy perspective. Accordingly, we also examine how the identified latent classes (segments) differ regarding socio-economic background and recreational use profiles.

\section{Material and methods}

\subsection{Case study}

Our case study deals with the recreational use of state-owned commercial forests (SOCFs) in Finland. Stateowned forests comprise a total of about 9 million hectares, or one third of Finland's forestry land. All stateowned lands are managed by Metsähallitus, a state-run enterprise that remits the profits from forestry as well as other business operations to the government. In addition, Metsähallitus has public administration duties, such as the management of conservation areas. A half of state-owned forests are commercially managed, while the other half consists of wilderness areas, national parks, and other protected areas. SOCFs are located mainly in the sparsely populated northern and eastern parts of Finland, at a distance from most of the largest Finnish cities. Still, Finland's SOCFs are estimated to host over ten million close-to-home (incl. leisure home) recreational visits annually (Sievänen and Neuvonen, 2011).

As the Act on Metsähallitus (2004) poses specific requirements to provide environmental services along with timber in SOCFs, the key principle in forest management is the multiple-use approach. For instance, to enhance recreation, specific management practices not typical of commercial forestry are applied, such as buffer zones along lakes, rivers and hiking trails to preserve wooded scenery. To implement the aimed multipurpose management, a strategic planning process called Natural Resources Planning (NRP) is utilized. The ecological issues are assessed and planned mainly at the landscape level, while other issues are assessed at the regional level, and all results are finally combined, analysed and reported at the regional level (Asunta et al., 2004). The idea of the NRP planning process is in generating a number of alternative management strategies which are analysed and evaluated in respect of various aspects of sustainability (Hiltunen, 2012). 
Thus, information about the attitudes and values of the local people and other stakeholders serves to ensure the social acceptability of the plans and activities in the operating environment.

\subsection{Survey design and data collection}

The data were collected with a survey questionnaire developed in spring 2012 in cooperation with forestry experts and tested with pilot interviews (for more detail, see Juutinen et al. 2014). The introductory part of the questionnaire was dedicated to recreational and attitudinal information. The questions were related to respondent's general knowledge about SOCFs, free time activities in SOCFs during the recent year and the previous and typical visits, and attitudes towards the multiple use of SOCFs. The second part introduced recreation-oriented management and the attributes used in the choice experiment (Table 1) by asking respondents to state their experience on the attributes. The introductory questions in this part guided the respondents to consider their own recreational experiences and the related forest management practices when answering the discrete choice tasks in the third part. The final part included questions regarding the respondent's socio-economic status.

The management attributes used in the discrete choice experiment (Table 1) were chosen so as to be relevant for both policy makers and the public (Bennett and Adamowicz, 2001). These were the width of scenic buffer zones along lakes and rivers, habitats for game birds in terms managed courting grounds for the capercaillie, and clear-cut areas visible along hiking trails. These three attributes represent the most typical management practices currently applied in SOCFs to enhance recreational services, and their relevance to the citizens was also supported by the pilot interviews. Notably, these practices also cause the main opportunity costs of recreation-oriented management. Since they reduce the profits of timber production that Metsähallitus remits to the government, a tax increase was used as the cost attribute.

[Table 1]

The purpose of common riparian buffer zones along lakes and rivers is to reduce the runoff of solid matters and nutrients from forestry areas into watercourses. However, buffer zones wider than what water protection 
requires are used to maintain the quality of scenery. ${ }^{1}$ Thus, the buffer zones in this study principally seek to preserve the wooded scenery in the landscape. The same applies to the courting grounds, which are habitats with mature pine forest surrounded by young (mixed) forest that provide favourable mating sites for the capercaillie. The courting grounds also increase the opportunity to see wildlife in the forest during outdoor activities (Boxall and Macnab, 2000). As clear-cutting with soil preparation is the most commonly perceived negative landscape effect of forestry (Ribe, 2005; Ribe, 2009; Silvennoinen et al., 2002; Tyrväinen et al., 2015), the quality of scenery along hiking trails was operationalized as the frequency of clear-cut regeneration areas visible along the trails. The status quo levels, based on the statistics of Metsähallitus (unpublished), refer to the nationwide average. The regional averages and individual respondents' experiences may differ from this. ${ }^{2}$ For each attribute, we specified the increase and the decrease in forest management activities, based on expert views on the potential future levels of recreation-oriented management in SOCFs.

To provide the respondents with sufficient information for the choices, the recreation-oriented management regime was described before the choice tasks. The respondents were first informed that Metsähallitus applies special management practices to enhance the provision of recreational services by SOCFs. Differences between the recreation-oriented and standard commercial management were illustrated by listing management activities used in the two regimes. It was also explained that recreation-oriented management practices reduce the profits of timber production remitted to the government, and that this reduction may be compensated for by increased taxes. The management-related attributes used in the choice experiment were then described verbally and graphically, and the respondents were asked to consider each attribute from the viewpoint of their own recreational experience and to choose their preferred attribute levels. They were informed that the presented levels describe the current management and potential future management practices for the next 10 years. The same levels were used in the choice experiment.

\footnotetext{
${ }^{1}$ The level that ensures protection against nutrient run-off is about 5 meters, which is the lowest attribute level for buffer zones used in this study.

${ }^{2}$ For a recent application with individual-specific status quo levels, see Ahtiainen et al. (2015).
} 
The combinations of attributes and their levels and the resulting 36 choice tasks (i.e., the experimental design) were created using an efficient design with prior information from the pilot survey and optimized for D-efficiency for the RPL panel model (Ngene, 2010). To rule out dominated alternatives due to a positive tax payment with decreases in all attributes, the level of at least one attribute was always required to be increasing. The tasks were blocked into six groups, thus each respondent faced six choice tasks in which s/he selected between three forest management alternatives. Each choice task included two future scenarios for the next 10 years (Alternatives 1 and 2) and a status quo alternative, in which the levels of attributes referred to the current situation. Figure 1 presents an illustration of the choice task.

[Figure 1]

The data were collected by a combination of mail and web surveys (a mixed mode) during summer 2012. An invitation to participate in the web-based survey was first sent to a total of 4200 randomly selected inhabitants of ages 18-75 years living in selected municipalities in three regions: Lapland, Kainuu, and Tavastia Proper (Fig. 2). The regions are equivalent to the Nomenclature of Units for Territorial Statistics (NUTS, level 3) of the European Union. After the invitation and one reminder, a second reminder accompanied by a printed questionnaire was sent to non-respondents. The received 1241 answers resulted in the response rate of $29.5 \%$. The majority $(59.0 \%)$ of respondents answered the paper version. The regionspecific response rate was highest in Kainuu (32.1\%) followed by Lapland (28.9\%) and Tavastia Proper $(27.6 \%)$

[Figure 2]

Regarding socio-demographic characteristics, such as age and gender, the samples were not significantly different from the respective populations, except for the age in Tavastia Proper (Table 2). The same applied to family size and household income (Juutinen et al. 2014). However, pensioners, farmers, cottage owners and highly educated citizens were somewhat over-represented in the sample. Regarding the share of urban residents, there are no official statistics available that match the classification of living environment used in this study, but the figures indicate that urban citizens were probably under-represented. In particular, the 
share of urban residents in southern Finland was likely to be greater than in the sample of Tavastia Proper since southern Finland includes the Helsinki metropolitan area. In addition, there are no official statistics of the members of environmental organizations, but these people likely participate more actively in surveys dealing with environmental issues.

[Table 2]

Addressing surveys to three regions targeted at covering citizens living at various socioeconomic situations and in areas with different opportunities to visit SOCFs. This would allow for revealing differences in recreational profiles across regions as well as the nationwide average. Regarding the different opportunities for forest visits, Lapland represents a region with plenty of SOCFs. Nature-based tourism has an important role in the region, and local people use the SOCFs actively. Kainuu also represents a region with abundant SOCFs. The large majority of the recreationists are local residents who participate very actively in close-tohome recreation. Tavastia Proper represents a southern region with almost no SOCFs at all. Most people in Finland live in the latter type of region.

\subsection{Models}

The analysis used binary probit, ordered probit and latent class models (for detailed descriptions, see Cramer, 2003; Train, 2009; Greene and Hensher, 2010). The binary probit model investigated factors explaining whether the respondent had visited SOCFs or not. The ordered probit model analysed factors affecting visitation frequency (the number of annual visits assessed at an ordered scale) to SOCFs. To avoid sample-selection bias, the binary and ordered models were integrated in a sample-selection model specification as described below. The latent class model (LCM) was used to analyse the discrete choice experiment data related to the management attributes of SOCFs.

The main part in the sample-selection model is the ordered model (Greene and Hensher, 2010), which takes into account the ordered nature of the observed outcomes and, correspondingly, ordered nature of the underlying preference scale. The structural equations for the ordered choice model are the following: 
$y_{n}^{*}=\alpha^{\prime} z_{n}+\varepsilon_{n}, n=1, \ldots, N$,

$y_{n}=0$ if $y_{n}^{*} \leq \mu_{0}$,

$y_{n}=1$ if $\mu_{0}<y_{n}^{*} \leq \mu_{1}$,

$y_{n}=\ldots$

$y_{n}=H$ if $y_{n}^{*}>\mu_{H-1}$,

in which $y_{n}^{*}$ denotes latent utility for individual $n$. In equation (1) $z_{n}$ denotes set of variables that are thought to influence the response to the survey question, $\alpha$ is a vector of utility coefficients of observed variable $z_{n}$, and $\varepsilon_{n}$ denotes a random error term following a standardized normal distribution. In equation (2) $y_{n}$ is observed discrete outcome $\left(y_{n}=0,1, \ldots, H\right)$, that is the visitation frequency in our case, and $\mu_{h}$ denotes unknown threshold parameters. The structural equations for the selection part, that is the binary probit model, are following:

$d_{n}^{*}=\eta^{\prime} k_{n}+u_{n}, n=1, \ldots, N$,

$d_{n}=1$ if $d_{n}^{*}>0$ and 0 otherwise,

in which the interpretation of notation is similar to the ordered model except that $d_{n}$ is the observed binary outcome which is visit or no visit in this study. The observation mechanism is: $y_{n}, z_{n}$ observed when $d_{n}=1$, $\left(\varepsilon_{n}, u_{n}\right) \sim N[(0,0),(0, \rho, 0)]$. Thus $d_{n}$ is endogenous, that is there is selectivity, if $\rho$ is not equal to zero.

The latent class model (LCM), used in the analysis of the discrete choice data (Boxall and Adamowicz, 2002; Greene and Hensher, 2003), can be derived from a random utility model, where the utility function of each respondent is the sum of a deterministic term, described as a function of factors that influence respondents' utility, and a random term that is unobservable and stochastic for the researcher. Assuming the existence of $S$ classes and that individual $n$ belongs to class $s(s=1, \ldots, S)$ the unobservable overall utility $U$ of alternative $i$ for a respondent $n$ is represented by:

$U_{n i s}=\beta_{s} x_{n i}+\varepsilon_{n i s}$ 
where $\beta_{s}$ is a class-specific vector of utility coefficients of observed variable $x_{n i}$ for respondent $n$ representing his/her preferences. The first part in the right hand side of equation (5) denotes the deterministic component and the last part a random component of the utility function.

Assuming a type I extreme value distribution for the random term $\varepsilon_{n i}$, the logit probability for choosing alternative $i$ conditional on class membership is defined as:

$$
L_{n \mid s}(i)=\frac{\exp \left(\mu_{s} \beta_{s} x_{i}\right)}{\sum_{k \in C} \exp \left(\mu_{s} \beta_{s} x_{k}\right)}
$$

where $C$ denotes the respondent's choice set and $\mu_{s}$ is a class-specific scale parameter. Next we can define the joint probability $P_{n}(i)$ that individual $n$ belongs to class $s$ and chooses alternative $i$ as follows:

$$
P_{n}(i)=\sum_{s=1}^{S} \pi_{n s} L_{n \mid s}(i)
$$

where $\pi_{n s}$ is the membership probability (see Boxall and Adamowicz 2002 for details). In the LCM, preference heterogeneity is accounted for by simultaneously assigning individuals into behavioural classes and estimating the choice model. Thus, preferences are assumed to be homogenous within each class, but vary between the classes.

Individual-specific variables included in the model explain the membership probability for each behavioural class. The estimated coefficients of attributes in the choice models and the membership probabilities $\pi_{s}$ for an individual to be assigned to class $s$ can be used to estimate the monetary valuations, reflected as willingness to pay, for changes in forest management practices, as follows

$$
E\left(W T P_{n}\right)=\sum_{s=1}^{S} \pi_{s}\left\{\frac{1}{\lambda_{s}}\left[\sum_{j=1}^{J} \beta_{j s}\left(x_{j}^{0}-x_{j}^{1}\right)\right]\right\},
$$

in which $\lambda_{s}$ denotes the coefficient of the cost attribute (marginal utility of income) for class $s$ and the 0 superscript refers to the initial state and the 1 superscript to the altered state following a change in at least one of the non-cost attributes $x_{j}^{1}$. Notice that in equations (5) and (6) $\beta_{s}$ is a vector that includes both the cost attribute and non-cost attributes. 


\section{Results}

\subsection{Recreational use of state-owned commercial forests}

The respondents were asked how many times they had visited SOCFs during the last 12 months. A sevenpoint ordered scale ranging from "not at all" to "over 50 times" was used. Figure 3 presents the frequency of visits to SOFCs across the respondents in the three regions. On average $65 \%$ of respondents visited SOCFs during the previous year. As reflected by the frequencies of 'no visits', citizens from Tavastia Proper visited SOCF less frequently (46\%) than did citizens from the two other regions (69\%), which is in line with the scarcity of SOCFs in southern Finland. Citizens from the Kainuu region were the most active users of SOCFs. For instance, about 34\% of citizens from Kainuu visited SOCFs more than 10 times during the last year. The corresponding figures for Lapland and Tavastia Proper were $26 \%$ and 6\%, respectively.

[Figure 3]

Those respondents who visited SOCFs during the last 12 months were asked to identify which activities they practiced during the visits in SOCFs. The three main types of outdoor activities were berry and mushroom picking; walking, running and hiking; and cross-country skiing (Fig. A1 in the appendix). Those who visited SOCFs had experienced on average 4.9 different outdoor activities during their visits during the last 12 months.

Table 3 presents the results of the ordered and binary logit model, elaborating on how individual-specific factors, such as socio-economic and outdoor activity-related variables, explain the use of SOCFs. ${ }^{3}$ The sample-selection model considers jointly both the decision to visit the SOCFs (visit/no visit) and the visitation frequency (ordered categories from "1-2 times" to "over 50 times") using the information in Figure 3. While a number of other explanatory variables were tested, only statistically significant variables were included in the reported final model. ${ }^{4}$ Along with socio-economic characteristics, the model includes

\footnotetext{
${ }^{3}$ The sample-selection ordered probit model was estimated with LIMDEP 10.0 software (Greene, 2012a).

${ }^{4}$ Basically, the potential explanatory variables for the models used in the analysis were selected based on theory (e.g., McFadden, 2001) as well as results from previous studies (e.g., Birol et al., 2006; Campbell et al., 2013; Tolvanen et al., 2013). However, as there are many potential variables which represent different indicators of the theoretically justified factors, we included only statistically significant variables in the final models and discuss the results regarding other tested variables. We systematically
} 
outdoor activities as explanatory variables to allow the identification of the most important outdoor activities affecting the use of SOCFs.

[Table 3]

First, the statistically significant coefficient of $\rho$ indicates that the use of the sample-selection approach was appropriate for avoiding selection bias. Second, the binary logit model shows that several socio-economic variables are statistically significant in explaining the decision to visit SOCFs. As expected based on results presented in Figure 3, citizens from Kainuu visited SOCFs more likely and citizens from Tavastia Proper less likely than the citizens from Lapland, which was the reference category. Citizens belonging to an environmental conservation organization, as well as cottage owners, visited SOCFs more likely. In contrast, farmers and forestry entrepreneurs (Farmer) visited SOCFs less likely than people with other occupational status. Being a pensioner, as well as the respondent's older age, also decreased the probability of visiting SOCFs. The Age and Pensioner variables correlated to some extent, but they both were included in the final model as it seemed that they also had independent roles in explaining the frequency of visits (and class memberships in the LCM as will be described in the next section). At least partly, this reflects the fact that our sample included a few quite young pensioners.

Third, according to the ordered logit model several socio-economic and activity variables explain the frequency of visits to SOCFs. Interestingly, these variables capture also the regional differences as the region variables ware not statistically significant in explaining the visitation frequency. Hence, aspects such as access to SOCFs or substitute forests may play an important role for the decision whether to visit SOCFs but their role is not that important regarding the frequency of visits to SOCFs. The likelihood of frequent visits to SOCFs was reduced if the respondent's place of residence was a city with more than 20,000 inhabitants (Urban) and increases if the respondent was a pensioner. Hence the group of pensioners seemed to be twofold: one part did not visit SOCFs whereas the other part used them quite frequently. Males used SOCFs more frequently than females. As reflected by the magnitude of model coefficients, the activities that were 
most typically associated with frequent visits to SOCFs were nature photography (including painting), grouse hunting and cycling. Recall that these activities were not the most commonly practiced ones (Fig. A1). Thus, their strong connection with visitation frequency indicates that by those engaged, these activities were practiced frequently although the number of enthusiasts was not very high. ${ }^{5}$

\subsection{Preferences for recreation-oriented management}

Based on the preferences towards recreation-oriented forest management attributes in the CE, the three classes from the LCM were labelled "Unresponsive", "Recreation supporters" and "Dissatisfied" (Table 4). The "Unresponsive" was the largest class with a class probability of $58 \%$. As revealed by the positive coefficient of the constant term, the respondents assigned to this class had a strong preference towards the features of current situation that are not related to the considered management attributes. In contrast, the respondents in this class were not very interested in, or familiar with, the recreation-oriented improvements in the management of SOCFs, since increases in management-related attributes were not statistically significant at the $10 \%$ level. They also responded negatively to a decrease in the width of buffer zones along lakes and rivers (Buffer5) and to an increase in clear-cut areas visible along hiking trails (Clearcut20), as reflected in the willingness to pay estimates of $€ 20.56$ and $€ 13.60$, respectively, for avoiding these effects (for calculation, see equation 8). Surprisingly, they responded positively to a decrease in game bird habitats (CourtingGround1). We return to a possible explanation to this result below.

[Table 4]

Almost one third of the respondents (class probability 28\%) were assigned to the "Recreation supporters" class (Table 4). The respondents in this class responded negatively to a decrease in recreation-oriented management. In addition, they placed a positive value to the increase of management activities except that

\footnotetext{
${ }^{5}$ Interestingly, an alternative specification with the number of outdoor activities practiced as an additional explanatory variable (not reported) suggested that some of the activities are "main activities" that serve as the main reason for the visits, while others are complementary or "bundled" activities practiced alongside other activities. However, the result should be interpreted with caution due to possible two-way causation between the annual numbers of visits and activities.

${ }^{6}$ We chose to use a 3-class model, based on a balanced assessment of the adjusted ${ }^{2}$, AIC and BIC statistics (Birol et al., 2006). The 3-class solution provided better fit with the data than a 2-class solution. Models with more than three classes did not converge. The LCM was estimated using NLOGIT 5.0 (Greene, 2012b).
} 
the decrease in clear-cut areas visible along hiking trails (Clearcut0) was not statically significant at the $10 \%$ level. Importantly, however, the current level of courting grounds was valued higher $(€ 18.62)^{7}$ than the increased level $(€ 8.08)$, and the value of current level of buffer zones $(€ 19.41)$ was close the value of increased level (€22.54). Thus this class seems to be quite satisfied with the current recreation-oriented management in SOCFs. It is worth mentioning that respondents in this class were claiming the lowest compensations (a negative WTP value) for the more intensive management of forest along hiking trails (Clearcut20).

About $14 \%$ of respondents were assigned to the class named "Dissatisfied". The respondents in this class placed the highest values for the changes in management activities compared to the current situation. They were not pleased with the current management and preferred to increase three management attributes. The values for increased levels of buffer zones (Buffer40, €158.37) and courting grounds (CourtingGround3, $€ 86.58)$ and reduced clear-cuts (Clearcut0, €84.88) were clearly higher than the values of current levels $€ 56.14, € 26.71, € 45.14$, respectively.

Respondents' socioeconomic characteristics explained probabilities to be assigned to classes (Table 4). In interpreting the class membership results, it must be taken into account that the "Dissatisfied" class was used as a reference category. Of the tested variables the respondent's age, highest education level (university degree) and pensioner status were significant and therefore used in the model. Respondents assigned to the "Unresponsive" class were characterized by a lower age, pensioner status, and education less than the highest level. Age and Pensioner were only weakly significant, but nevertheless their different signs suggest that the impact of aging may not be linear and that the pensioner status reflects also factors not related to the age. Also members of the "Recreation supporters" class had a lower age (weakly significant). Hence the "Recreation supporters" were similar to the "Unresponsive" in this respect, but the respondents in the "Dissatisfied" class were likely not pensioners and were older than the respondents in the other two classes. The "Recreation supporters" and the "Dissatisfied" were similar regarding the education and being not

\footnotetext{
${ }^{7}$ Given that effects coding was used, the value of the current state (omitted level) is obtained as the difference between the altered (non-status quo) levels (Bech and Gyrd-Hansen, 2005): $18.62=-1 *(8.08-26.70)$.
} 
pensioners: the members of these two classes had more often the highest education unlike the "Unresponsive" class.

Regarding factors related to outdoor activities, the membership probabilities were explained by three variables: the respondent had not visited SOCFs during the last 12 months (Novisit), had practiced nature watching during the visit (Nature watching), or had practiced net fishing, spinning, trolling or fly fishing during the visit (Fishing). Respondents in the "Unresponsive" class had typically not visited SOCFs during the last 12 months. Respondents who had practiced nature watching or fishing (weakly significant) during their visit were not likely members of the "Unresponsive" class. Fishing (weakly significant) and nature watching (weakly significant) reduced also the membership probability of the "Recreation supporters". Thus we can conclude that fishing and nature watching increased the probability of being a member of the Dissatisfied class, which indicates that respondents in this class were active users of SOCFs.

\section{Discussion}

Our results show that the recreational use of SOCFs differs among the studied regions, that citizens have various recreational needs depending on their background and specific outdoor activities, and that the heterogeneity of preferences for forest management practices is related to citizens' socioeconomic characteristics and recreational profiles, but not to the regions. People living in the principally rural regions of northern and eastern Finland were observed to use SOCFs more actively for recreation activities than people in southern Finland, where the majority of the population lives. The results are in line with the national outdoor recreation surveys demonstrating that citizens of eastern Finland participate most actively in outdoor recreation (Sievänen and Neuvonen, 2011). Ezebilo et al. (2015) also found in Sweden that people who live in rural areas are more frequent visitors to nature areas for outdoor recreation than people in urban areas. Compared with the private forest and municipally owned forest areas in Finland, SOCFs are used in particular for consumptive use including berry and mushroom picking, hunting, and fishing (Kosenius et al., 2013; Sievänen and Neuvonen, 2011). These activities were quite frequent also in our study. The different user profile of SOCFs compared to private and municipally owned forests likely reflects the fact that SOCFs are typically located further away from the place of residence. For example, municipal 
areas are frequently used for daily outdoor recreation activities such as walking and jogging (Sievänen and Neuvonen, 2011).

We found evidence of substantial preference heterogeneity towards the studied recreation-oriented forest management attributes. The latent class model revealed three classes. The first class, "Unresponsive", preferred the current management alternative, but the members of this class were likely not very familiar with the management of SOCFs given that they had typically not visited SOCFs during the last 12 months. Thus, to some extend this outcome may reflect status quo bias (Haefen et al., 2005), but it also indicates that the members of this class were satisfied with the current management practices (Thiene et al., 2012; Juutinen et al., 2014). The members of the second class, "Recreation supporters", were also quite satisfied with the current situation given that they placed high WTP values for the current management levels. The members of the third class, "Dissatisfied", preferred increases in the recreation-oriented management attributes. In a previous study Juutinen et al. (2014) found regional differences in preferences by estimating separate random parameters models for each region (Lapland, Kainuu, Tavastia Proper). Interestingly, the present study showed that preference heterogeneity could be explained by respondents' socio-economic characteristics and recreational use profiles, whereas the regions were not significant explanatory variables along with the respondents' characteristics.

Visitors of SOCFs had higher monetary valuations for recreation-oriented management than had nonvisitors. Specifically, respondents who practiced nature watching or fishing during the visit had the highest valuations. Thus, the valuations for recreation-oriented management were largely related to the respondents' recreational use profiles, i.e., to use values rather than non-use or option values. Another likely reason for placing higher importance on the recreation-oriented management is that respondents who had visited SOCFs in the last 12 months can be expected to be more experienced and have better knowledge of different management alternatives. Similarly, Hanley et al. (1998) showed that non-users have lower valuations for landscape improvements. In addition, Czajkowski et al. (2014) showed that non-users were generally more satisfied with the current forest management, whereas the users were willing to pay to avoid the status quo. 
Christie at al. (2007) showed that specialist forest user groups attain generally higher values for improvements than general users.

The surprising result regarding the courting grounds attribute for the "Unresponsive" class may be related to their infrequent visits to SOCFs, hence the lack of familiarity with the current management. For such a less informed segment the information presented in the questionnaire may not have been sufficient to give a precise view of the meaning of the attribute. Thus, the attribute's intendedly scenic role may have been in part confused with unintended aspects such as the increase of hunting opportunities which is probably regarded as a negative outcome by some respondents.

Regarding specific attributes, we found that scenic buffer zones along lakes and rivers were most important for the citizens. Wider buffer zones had a clear positive effect on the citizens' welfare, excluding members of the "Unresponsive" class. In contrast Holmes and Boyle (2003) found that riparian buffers had no significant effect. Notice, however, that rather than being riparian water protection zones required by the Water Act, the buffer zones in our case were based principally on scenic considerations. The scenic aspect of the buffer zones is directly observable to the citizens and likely emphasized in a country with a vast amount of lakes like Finland. In addition, our results showed that less frequent clear-cut areas along hiking trails and the increased provision of habitats for game birds had a positive effect on the citizens' welfare, excluding members of the "Unresponsive" class. These findings are in line with earlier studies that have examined the importance of the quality of landscape and opportunity to see wildlife for outdoor visitors (Adamowicz et al., 1997; 1998; Hanley et al., 1998; Boxall and Macnab, 2000; Silvennoinen et al., 2002; Holmes and Boyle, 2003; Horne et al. 2005; Ribe, 2005, 2009; Tyrväinen et al., 2014). However, it must be kept in mind that the studied management attributes represent a wider set of recreation-oriented management alternatives. For example, avoiding clear-cuttings along hiking trails and using wider buffer zones along waters to preserve the wooded scenery typically involves various selective harvesting practices that were not specified in this study. Specific management practices also depend on the characteristics of the site.

\section{Conclusions}


Our results clearly show the diversity of citizens' recreational patterns and expectations regarding forest management. As the preferences vary, it is probably unrealistic to expect that all people would agree on the chosen management regimes. This calls for a continuous readiness for compromises in the management. In the present case of state-owned commercial forests in Finland, the current recreation-oriented management regime is widely accepted. In the future, however, the demands for recreational and conservation orientation may increase due to the citizens' increasing environmental awareness. To further improve the public acceptance of forest management, recreation and conservation of habitats probably need to be considered more widely in the planning and decision making concerning forest management. To understand changes in citizens' preferences and outdoor recreation patterns, information needs to be collected regularly.

Understanding the heterogeneity of citizens' preferences and factors behind their recreational preferences is important because it helps the decision-makers to choose widely preferred and accepted management practices. The particular policy relevance of the LCM approach lies in the fact that it allows the identification of distinct segments of preferences with their relative sizes and background characteristics, hence more detailed management implications. For example, if the managers of SOCFs wish to maximize the recreation-related benefits to the citizens, the obvious policy is "management for the many", i.e., the majority's preferences should count. From this point of view, the maintenance (or increase) of the scenic buffer zones along waters was a clear preference shared by all segments of respondents. The same more or less applies to the avoidance of clear-cuttings along hiking trails.

Overall, once the majority of respondents - especially the "Unresponsive" class that alone makes a majority of $58 \%$ - were quite satisfied with the current management, the results do not seem to suggest any major management changes. However, this may be an over-simplified interpretation. Given that respondents assigned to the "Unresponsive" class, having typically not visited SOCFs during the last year, were likely not very familiar with the current management, a natural question is to what extend the preferences of frequent users of SOCFs - especially the "Dissatisfied" class with nature watchers and fishing visitors - who are likely to be better informed, should be emphasized. Another matter of principle that is up to the 
managers to decide is whether the management of SOCFs is to be uniform or differentiated across geographic regions.

\section{Acknowledgements}

This research was funded by Metsähallitus and Finnish Forest Research Institute (Metla). The authors are grateful to Tapio Pouta, Pauli Wallenius, Martti Aarnio, Johanna Leinonen, Lauri Karvonen, and Mervi Väisänen of Metsähallitus for co-operation and for helping them to choose the attributes and their levels for the CE. Irene Murtovaara at the Natural Resources Institute Finland is acknowledged for carrying out the layout of the mail questionnaire, and Keijo Kallunki at Metsähallitus for programming the web-based survey.

\section{References}

Act on Metsähallitus 1378/2004. Ministry of Agriculture and Forestry, Finland. Available: http://www.finlex.fi/fi/laki/kaannokset/2004/en20041378.pdf, Accessed: January 09, 2013.

Adamowicz, W., Swait, J., Boxall, P., Louviere, J., Williams, M., 1997. Perceptions versus objective measures of environmental quality in combined revealed and stated preference models of environmental valuation. Journal of Environmental Economics and Management 32, 65-84.

Adamowicz, W., Boxall, P., Williams, M., Louviere, J., 1998. Stated preference approaches for measuring passive use values: Choice experiments and contingent valuation. American Journal of Agricultural Economics 80, 64-75.

Ahtiainen, H., Pouta, E., Artell, J., 2015. Modelling asymmetric preferences for water quality in choice experiments with individual-specific status quo alternatives. Water Resources and Economics, 1-39.

Asunta, A., Hiltunen, V., Väisänen, M. (Eds.), 2004. Metsähallituksen luonnonvarasuunnittelu. Suunnitteluohje. Metsähallitus. Edita Prima Oy, Helsinki. 75 p.

Bech, M., Gyrd-Hansen, D., 2005. Effects coding in discrete choice experiments. Health Economics 14, 1079-1083.

Bennett, J., Adamowicz, V., 2001. Some Fundamentals of Environmental Choice Modelling. In: Bennett, J. and Blamey, R. (eds.) The Choice Modelling Approach to Environmental Valuation. Northampton: Edward Elgar Publishing. 37-72.

Birol, E., Karousakis, K. Koundouri, P., 2006. Using a choice experiment to account for preference heterogeneity in wetland attributes: The case of Cheimaditida wetland in Greece. Ecological Economics 60, 145-156.

Boxall, P.C., Macnab, B., 2000. Exploring the preferences of wildlife recreationists for features of boreal forest management: A choice experiment approach. Canadian Journal of Forest Research 30, 1931-1941. 
Boxall, P.C., Adamowicz, W.L. 2002. Understanding heterogeneous preferences in random utility models: a latent class approach. Environmental and Resource Economics 23, 421-446.

Campbell, D., Vedel, S., Thorsen, B., Jacobsen, J., 2013. Heterogeneity in the WTP for recreational access: distributional aspects. Journal of Environmental Planning Management 57, 1200-1219.

Cramer, J.S., 2003. Logit models. From economics and other fields. Cambridge University Press, UK.

Czajkowski, M., Bartczak, A., Giergiczny, M., Navrud, S., Zylicz, T. 2014. Providing preference-based support for forest ecosystem service management. Forest Policy and Economics 39, 1-12.

Christie, M., Hanley, N., Hynes, S., 2007. Valuing enhancements to forest recreation using choice experiment and contingent behavior methods. Journal of Forest Economics 13, 75-102.

Ezebilo, E., Boman, M., Mattson, L., Lindhagen, A., Mbongo, W. 2015. Preferences and willingness to pay for close to home nature for outdoor recreation in Sweden. Journal of Environmental Planning and Management 58, 283-296.

FAO, 1998. Forestry policies in Europe - An analysis. FAO Forestry Paper 86, FAO Rome.

Greene, W., 2012a. Limdep, version 10. Reference guide. Econometric Software, Inc.

Greene, W., 2012b. Nlogit, version 5. Reference guide. Econometric Software, Inc.

Greene, W., Hensher, D., 2003. A latent class model for discrete choice analysis: Contrasts with mixed logit. Transportation Research Part B, 37, 681-698.

Greene, W., Hensher, D., 2010. Modeling ordered choices. A primer. Cambridge University Press, UK.

Gundersen, V.S., Frivold, L.H., 2008. Public preferences for forest structures: a review of quantitative surveys from Finland, Norway and Sweden. Urban Forestry and Urban Greening 7, 241-258.

Hanley, N., Wright, R., Adamowicz, W., 1998. Using choice experiments to value the environment: Design issues, current experience and future prospects. Environmental and Resource Economics11, 413-428.

Haefele, M.A., Loomis, J.B., 2001. Using the conjoint analysis technique for the estimation of passive use values of forest health. Journal of Forest Economics 7, 9-28.

Haefen, R., Massey, M., Adamowicz, W., 2005. Serial nonparticipation in repeated discrete choice models. American Journal of Agricultural Economics 87, 1061-1076.

Hiltunen, V. 2012. Developing decision support in participatory strategic forest planning in Metsähallitus. University of Eastern Finland, School of Forest Sciences. Dissertationes Forestales 14.

Holmes, T.P., Boyle, K.J., 2003. Stated preference methods for valuation of forest attributes. In: Sills, E., and Abt, K. (eds.) Forests in a Market Economy. Kluwer Academic Publishers. Pp. 321-340.

Horne, P., Boxall, P.C., Adamowicz, W.L., 2005. Multiple-use management of forest recreation sites: a spatially explicit choice experiment. Forest Ecology and Management 207, 189-199.

Hummel, F.C., 1992. Aspects of forest recreation in Western Europe. Forestry 65, 237-251.

Jackson, L.E., 1986. Outdoor recreation participation and attitudes to the environment. Leisure Studies 5, 123.

Jackson, L. E., 1987. Outdoor recreation participation and views on resource development and preservation. Leisure Studies 9, 235-250. 
Jensen, F., 1995. Forest recreation. In: M. Hytönen (Ed.) Multiple-use forestry in the Nordic countries. The Finnish Forest Research Institute. Helsinki. Pp. 245-278.

Juutinen, A., Kosenius, A.K., Ovaskainen V., 2014. Estimating the benefits of recreation-oriented management in state-owned commercial forests in Finland: A choice experiment. Journal of Forest Economics 20, 396-412.

Kosenius, A.-K., Juutinen, A., Neuvonen, M., Ovaskainen, V., Sievänen, T., Tolvanen, A., Tyrväinen, L., 2013. Virkistyskäyttöä edistävä metsänhoito valtion talousmetsissä: hyötyjen rahamääräinen arvo.

[Recreation-enhancing management of state-owned commercial forests: monetary benefits.] Working Papers of the Finnish Forest Research Institute 261, 60 p.

Manning, R., 2010. Studies in Outdoor Recreation. Search and Research for Satisfaction. Third Edition. Oregon State University Press. ISBN 978-0-87071-590-7. 448 p.

McFadden, D., 2001. Economic choices. The American Economic Review 91, 351-378.

Ngene, 2010. User manual and reference guide. The cutting edge in experimental design. ChoiceMetrics. $230 \mathrm{p}$.

Nielsen, A.B., Olsen, S.B., Lundhede, T., 2007. An economic valuation of the recreational benefits associated with nature-based forest management practices. Landscape and Urban Planning 80, 63-71.

Ribe, R., 1989. The Aesthetics of Forestry: What has Empirical Preference Research Taught Us? Journal of Environmental Management 13, 55-74.

Ribe, R., 2005. Aesthetic perceptions of green-tree retention harvests in vista views The interaction of cut level, retention pattern and harvest shape. Landscape and Urban Planning 73, 277-293.

Ribe, R., 2009. In-stand scenic beauty of variable retention harvests and mature forests in the U.S. Pacific Northwest: the effects of basal area, density, retention pattern and down wood. Journal of Environmental Management 91, 245-260.

Roovers, P., Marny, M., Gulinck, H., 2002. Visitor profile, perceptions and expectations in forests from a gradient of increasing urbanization in central Belgium. Landscape and Urban Planning 59, 129-145.

Schaberg, R.H., Homes, T.P., Lee, K.J., Abt, R.C., 1999. Ascribing value to ecological processes: An economic view of environmental change. Forest Ecology and Management 114, 329-338.

Sievänen, T., Neuvonen, M., 2011. Luonnon virkistyskäyttö 2010 [Recreation in the nature 2010]. Working Papers of the Finnish Forest Research Institute 212, 190 p.

Silvennoinen, H., Pukkala, T., Tahvanainen, L., 2002. Effect of cuttings on the scenic beauty of a tree stand. Scandinavian Journal of Forest Research 17, 263-273.

Thiene, M., Meyerhoff, J., De Salvo, M., 2012. Scale and taste heterogeneity for forest biodiversity: models of serial nonparticipation and their effects. Journal of Forest Economics 18, 355-369.

Tolvanen, A., Juutinen, A., Svento, R., 2013. Preferences of local people for the use of peatlands: The case of peatland-richest region in Finland. Ecology and Society, 18 (2): 19.

Train, K., 2009. Discrete Choice Methods with Simulation. 2nd ed. Cambridge: Cambridge University Press.

Tyrväinen, L., Mäntymaa, E., Ovaskainen, V., 2014. Demand for enhanced forest amenities in private lands: The case of the Ruka-Kuusamo tourism area, Finland. Forest Policy and Economics 47, 4-13. 
Tyrväinen, L., Silvennoinen, H., Hallikainen, V., 2015. Effect of the season and forest management on the quality of the tourist environment: Case from Finnish Lapland. (submitted manuscript). 18 p.

Tyrväinen, L., Buchecker, M., Vuletic, D., Degenhart, B., 2008. Evaluating the economic and social benefits of forest recreation and nature tourism. In: Bell, S., Simpson, S., Tyrväinen, L., Sievänen, T. \& Pröbstl, U. (eds.). European forest recreation and tourism: A handbook. Taylor and Francis Group Plc., London. p. 3564. 


\section{Appendix}

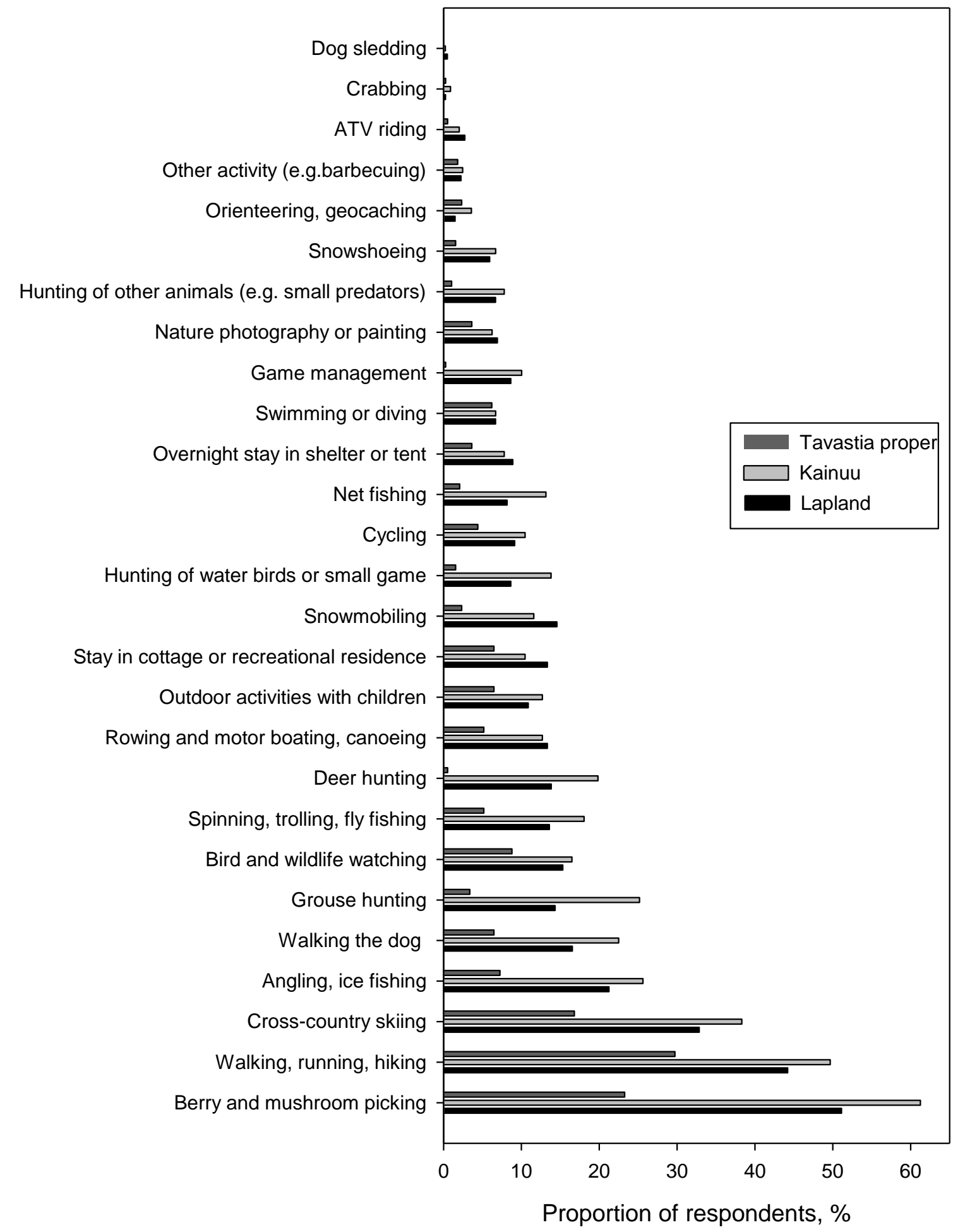

Figure A1. Outdoor activities practiced during the visits in state owned commercial forest during last 12 months by region. 
Table 1. Attributes and attribute levels with variable names used in the analysis.

\begin{tabular}{|c|c|c|}
\hline Attribute & Level & Variable name ${ }^{a}$ \\
\hline Width of buffer zones along & 1. 5 meters & Buffer5 \\
\hline \multirow[t]{2}{*}{ lakes and rivers } & 20 meters (current level) & Buffer40 \\
\hline & 40 meters & \\
\hline Number of managed courting & 1000 & CourtingGround1 \\
\hline \multirow[t]{2}{*}{ grounds for capercaillie } & 2. 2000 (current level) & CourtingGround3 \\
\hline & 3. 3000 & \\
\hline Clear-cut areas visible along & 1. Quite frequently (20\%) & Clearcut20 \\
\hline \multirow[t]{2}{*}{ hiking trails (on \% of trails) } & Quite rarely (10\%, current level) & Clearcut0 \\
\hline & 3. Not at all $(0 \%)$ & \\
\hline Tax increase per household & $0,10,30,60,100,150$ (€/year) & Tax \\
\hline
\end{tabular}


Table 2. Comparison of samples and populations (regional averages).

\begin{tabular}{|c|c|c|c|c|c|c|}
\hline & \multicolumn{2}{|c|}{ Lapland } & \multicolumn{2}{|c|}{ Kainuu } & \multicolumn{2}{|c|}{ Tavastia Proper } \\
\hline & Sample & Population & Sample & Population & Sample & Population \\
\hline $\mathrm{N}$ & 405 & 183488 & 449 & 82073 & 387 & 4935160 \\
\hline Male (\%) & 47.7 & 50.2 & 52.2 & 50.0 & 48.0 & 49.3 \\
\hline Age (years) & 51.6 & 51.3 & 53.2 & 52.7 & ***52.7 & 49.6 \\
\hline Pensioner (\%) & *31.9 & 27.7 & *34.9 & 31.0 & **28.7 & 24.0 \\
\hline Urban (\%) & 18.5 & - & 21.6 & - & 18.9 & - \\
\hline Farmer (\%) & 2.9 & 1.5 & ** 4.0 & 1.9 & $* * * 4.2$ & 1.6 \\
\hline Cottage owner (\%) & 41.7 & 37.7 & $* * * 47.3$ & 36.0 & *43.2 & 38.9 \\
\hline $\begin{array}{l}\text { Member of environmental } \\
\text { organization (\%) }\end{array}$ & 2.5 & - & 1.6 & - & 3.9 & - \\
\hline $\begin{array}{l}\text { High education (\% of university } \\
\text { degree) }\end{array}$ & $* \star * 8.6$ & 4.9 & $* * * 7.8$ & 4.4 & 10.9 & 8.7 \\
\hline
\end{tabular}

Notes: The Urban variable includes ( $1=y e s, 0=n o)$ respondents those place of residence is a city with more than 20,000 inhabitants. The data on population are from Statistics Finland (2012). The sample of Tavastia Proper is compared with the population of Finland excluding populations from Lapland and Kainuu. ${ }^{*}$ ) $10 \%$ significance level, ${ }^{* *}$ ) $5 \%$ significance level, ${ }^{* *}$ ) $1 \%$ significance level (one sample $t$ test) 
Table 3. Factors explaining the use of state owned commercial forests for recreation purposes. Coefficient SD $\quad$-value

Ordered model: frequency of visits (measured at ordered scale)

Constant and socio-economic variables

\begin{tabular}{lccc} 
Constant & -.22940 & .13134 & .0807 \\
Urban & -.38904 & .10360 & .0002 \\
Male & .00066 & .00033 & .0462 \\
Pensioner & .30882 & .09132 & .0007 \\
Outdoor activities & & & \\
Skiing & .41390 & .08526 & .0000 \\
Snowshoeing & .43052 & .14594 & .0032 \\
Snowmobiling & .26359 & .10478 & .0119 \\
Cycling & .53371 & .11286 & .0000 \\
Walking, running & .22760 & .08500 & .0074 \\
Walking the dog & .34815 & .09248 & .0002 \\
Orienteering & .39200 & .19950 & .0494 \\
Berry picking & .38563 & .09013 & .0000 \\
Nature photography & .53789 & .12716 & .0000 \\
Bird watching & .22871 & .09764 & .0192 \\
Spinning, fly fishing & .24551 & .10445 & .0187 \\
Game management & .30236 & .14828 & .0414 \\
Deer hunting & .31236 & .12966 & .0160 \\
Grouse hunting & .53597 & .11268 & .0000 \\
Threshold parameters & & & \\
Mu(1) & .64222 & .05255 & .0000 \\
Mu(2) & 1.11558 & .07185 & .0000 \\
Mu(3) & 1.68132 & .09691 & .0000 \\
Mu(4) & 2.36605 & .12782 & .0000 \\
\hline Constant & 1.26991 & .19248 & \\
Tavastia Proper & -.86440 & .09602 & .0000 \\
Kainuu & .21393 & .09525 & .0000 \\
Farmer & -.40179 & .20592 & .0247 \\
Pensioner & .28493 & .10559 & .0070 \\
Cottage owner & .14863 & .07783 & .0562 \\
Age & -.00906 & .00346 & .0089 \\
Environ. organization member & .57450 & .27419 & .0361 \\
Rho (u, e) & -.62289 & .09966 & .0000 \\
\hline Log likelihood & -1726.0 & & \\
AlC & 3514.0 & & \\
\hline
\end{tabular}


Table 4. Estimation results for the latent class model.

\begin{tabular}{|c|c|c|c|c|}
\hline & Coefficient & SD & $p$-value & WTP \\
\hline \multicolumn{5}{|c|}{$\begin{array}{l}\text { Class 1: "Unresponsive", } \\
\text { membership probability } 58 \%\end{array}$} \\
\hline Constant & 2.70326 & .68765 & .0001 & \\
\hline Buffer5 & -.68272 & .27668 & .0136 & -20.56 \\
\hline Buffer40 & .09863 & 20378 & .6284 & \\
\hline CourtingGround1 & .44632 & .24135 & .0644 & 13.44 \\
\hline CourtingGround3 & .17248 & 20987 & .4112 & - \\
\hline Clearcut20 & -.45145 & .24555 & .0660 & -13.60 \\
\hline Clearcut0 & .03823 & .20821 & .8543 & - \\
\hline Tax & -.03320 & .00692 & .0000 & \\
\hline \multicolumn{5}{|c|}{$\begin{array}{l}\text { Class 2: "Recreation supporters", } \\
\text { membership probability } 28 \%\end{array}$} \\
\hline Constant & -1.48071 & 24416 & .0000 & \\
\hline Buffer5 & -1.19796 & .14320 & .0000 & -41.95 \\
\hline Buffer40 & .64372 & .11300 & .0000 & 22.54 \\
\hline CourtingGround1 & -.76258 & 10756 & .0000 & -26.70 \\
\hline CourtingGround3 & 23079 & .08911 & .0096 & 8.08 \\
\hline Clearcut20 & -.29641 & 10105 & .0034 & -10.38 \\
\hline Clearcut0 & .04603 & .09154 & .6151 & \\
\hline Tax & -.02856 & .00212 & .0000 & \\
\hline \multicolumn{5}{|c|}{$\begin{array}{l}\text { Class 3: "Dissatisfied", } \\
\text { membership probability } 14 \%\end{array}$} \\
\hline Constant & -1.63818 & .26319 & .0000 & \\
\hline Buffer5 & -1.13689 & .14641 & .0000 & -214.51 \\
\hline Buffer40 & .83938 & 12063 & .0000 & 158.37 \\
\hline CourtingGround1 & -.60044 & .11644 & .0000 & -113.29 \\
\hline CourtingGround3 & .45888 & .11559 & .0001 & 86.58 \\
\hline Clearcut20 & -.68908 & 12336 & .0000 & -130.02 \\
\hline Clearcut0 & .44987 & 10901 & .0000 & 84.88 \\
\hline Tax & -.00530 & .00137 & .0001 & \\
\hline \multicolumn{5}{|c|}{ Class 1: class membership parameters } \\
\hline Constant & 2.30092 & .55032 & .0000 & \\
\hline Age & -.01775 & .00982 & .0707 & \\
\hline HighEducation & -.82584 & .30284 & .0064 & \\
\hline Pensioner & .52016 & 27974 & .0630 & \\
\hline NoVisit & .48488 & 23814 & .0417 & \\
\hline Nature watching & -.58730 & 25510 & .0213 & \\
\hline Fishing & -.48626 & .25723 & .0587 & \\
\hline \multicolumn{5}{|c|}{ Class 2: class membership parameters } \\
\hline Constant & 2.62535 & .60632 & .0000 & \\
\hline Age & -.03514 & 01112 & .0016 & \\
\hline HighEducation & -.30076 & .36652 & .4119 & \\
\hline Pensioner & .51786 & .34244 & .1305 & \\
\hline NoVisit & -.05459 & 28826 & .8498 & \\
\hline Nature watching & -.50549 & .30678 & .0994 & \\
\hline Fishing & -.52798 & .31195 & .0905 & \\
\hline Log likelihood & 3813.3 & & & \\
\hline AIC & 7702.7 & & & \\
\hline pseudo R-squared & 0.4904 & & & \\
\hline
\end{tabular}




\section{Figure captions}

Figure 1. An example of the choice task.

Figure 2. The state-owned commercial forests (SOCFs) in Finland and the three sampling regions.

Figure 3. Frequency of visits to state owned commercial forests during last 12 months by region.

Figure A1. Outdoor activities practices during the visits in state-owned commercial forest during the last 12 months by region.

\begin{tabular}{|l|c|c|c|}
\hline Choice task I & Current situation & Alternative I & Alternative 2 \\
\hline $\begin{array}{l}\text { Width of buffer zones along lakes } \\
\text { and rivers }\end{array}$ & $20 \mathrm{~m}$ & $40 \mathrm{~m}$ & $20 \mathrm{~m}$ \\
\hline $\begin{array}{l}\text { Number of managed courting grounds } \\
\text { for capercaillie }\end{array}$ & 2000 & 1000 & 3000 \\
\hline $\begin{array}{l}\text { Clear-cut areas visible along hiking } \\
\text { trails }\end{array}$ & quite rarely & not at all & not at all \\
\hline Tax increase per household & $0 € /$ year & $10 € /$ year & $30 € /$ year \\
\hline $\begin{array}{l}\text { In my opinion, the best alternative is } \\
\text { (please tick one circle) }\end{array}$ & 0 & 0 & \\
\hline
\end{tabular}

Figure 1. 


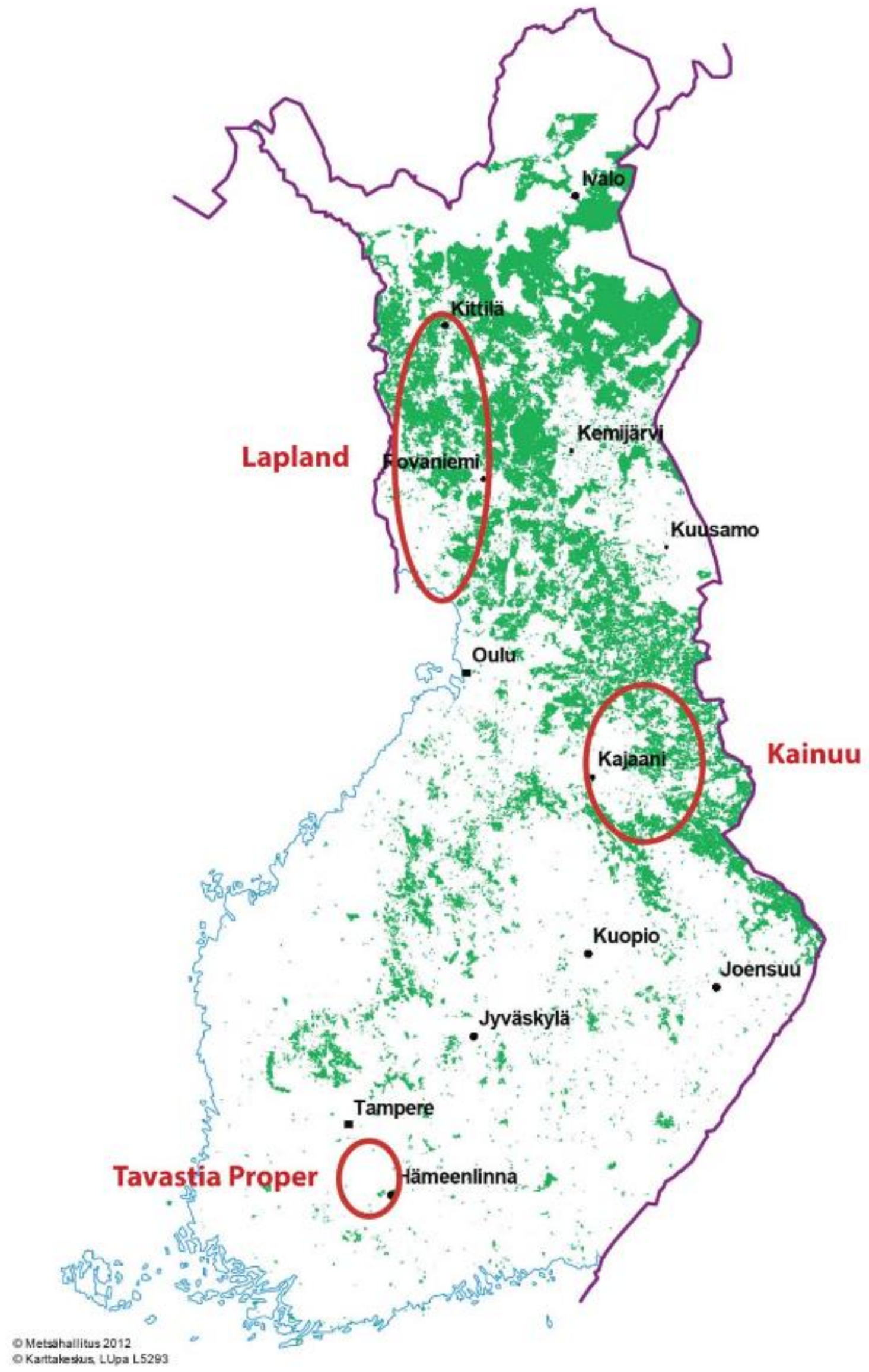

Figure 2. 


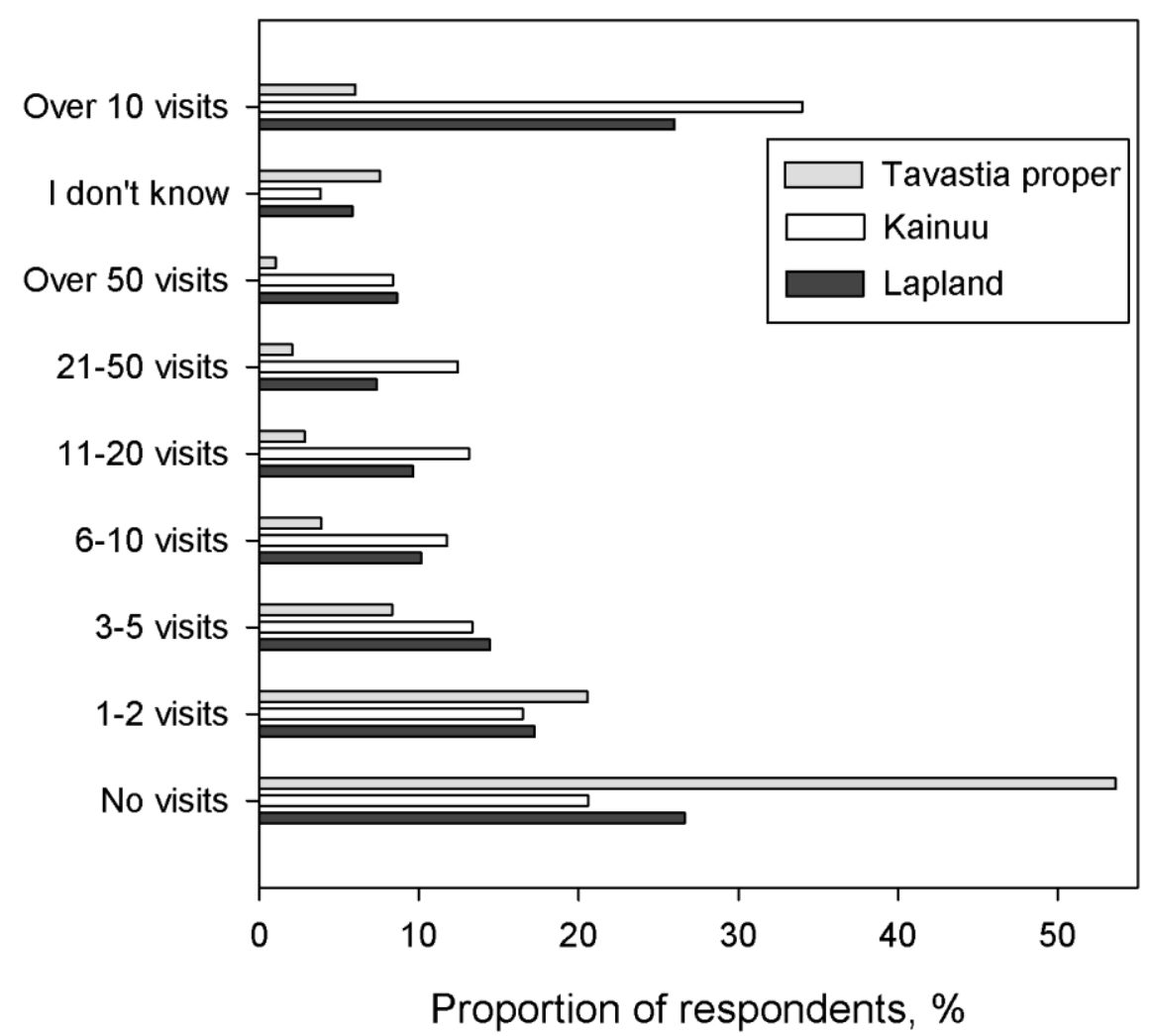

Figure 3. 